\title{
A Potential Benefit of Quercetin in Preserving Tight Junction Integrity
}

\author{
Somrudee Chuenkitiyanon ${ }^{\mathrm{a}}$, Nontima Vardhanabhuti ${ }^{\mathrm{b}}$ and Suree Jianmongkol ${ }^{\mathrm{c}, *}$
}

${ }_{a}^{a}$ Interdisciplinary Program in Pharmacology, Graduate School, Chulalongkorn University, Bangkok 10330, Thailand
${ }^{b}$ Department of Pharmaceutics and Industrial Pharmacy, Faculty of Pharmaceutical Sciences, Chulalongkorn
University, Bangkok 10330, Thailand

${ }^{c}$ Department of Pharmacology and Physiology, Faculty of Pharmaceutical Sciences, Chulalongkorn University, Bangkok 10330, Thailand

\begin{abstract}
Disruption of tight junction (TJ) integrity can occur from loss of TJ protein expression and/or disorganization. Consequently, epithelial/endothelial barriers lose their barrier functions in the control over paracellular transport, leading to the compromised defense mechanism of the organ. The TJ disruption has been related to multiple signal transduction pathways including mitogen-activated protein kinases (MAPK). Quercetin is one of the most widely studied flavonoids with broad spectrum of pharmacological activities. In addition to antioxidant capability, quercetin may exert its actions via the alteration of protein kinase activities and the sequential signaling processes. This may enable quercetin to prevent the disintegration of TJ structure and to enhance the expression, localization and interaction of TJ proteins. This review presents the information to corroborate the potential benefit of quercetin in preserving integrity and function of TJ complexes. The involvement of protein kinase C (PKC) and MAPK signaling pathway is emphasized.
\end{abstract}

Keywords: Quercetin, tight junction, protein kinases.

\section{INTRODUCTION}

Epithelial and endothelial tissues, which line up the cavities and surfaces of organ throughout our body, act as strong protective barriers against pathogens and chemical invasion. In these tissues, the epithelial/ endothelial cells are tightly connected with special intercellular bonding including gap junctions, desmosomes, adherence junctions and tight junctions (TJ) to seal the gap between them [1,2]. The extracellular TJ architecture at the apical site regulates the paracellular movement of ions, solutes and immune cells across the epithelia and endothelia (barrier function). In addition, the TJ structure assists the cells in holding together as well as creates cell polarity to block the movement of integral membrane proteins between the apical and the basolateral sites (fence function) [3-6]. Disruption of TJ structure and function results in hyperpermeability and leakage of epithelial and endothelial barriers, which is a condition involved in a number of pathologic states such as inflammatory bowel disease (IBD), renal failure, edema jaundice, diarrhea, and blood-borne metastasis [7, 8]. Although the mechanisms of TJ assembly, maintenance and disruption are not fully elucidated, the potential benefits of several food components and compounds including quercetin, glutamine, epidermal growth factor (EGF) in enhancing and preserving TJ integrity have been identified [8-10].

\footnotetext{
*Address correspondence to this author at the Department of Pharmacology and Physiology, Faculty of Pharmaceutical Sciences, Chulalongkorn University, Bangkok 10330, Thailand; Tel: +662 218 8318;

Fax: +662 218 8324; E-mail: sureejmk@yahoo.com
}

\section{THE TIGHT JUNCTION: ITS COMPONENTS AND THE ROLES OF MAPKS}

TJ complex is formed through interactions between a number of integral membrane proteins (e.g., occludin, claudin, junctional adhesion molecule or JAM), peripheral proteins (the zonular occludens (ZO) family including ZO-1, $\mathrm{ZO}-2$, and ZO-3) and other junction-associated proteins (e.g., cingulin) [3, 4, 6, 11, 12]. Occludin and claudin are structural junction proteins that connect to the actin cytoskeleton through cytoplasmic $\mathrm{ZO}$ linkers $[3,4,13]$. The interactions between JAM, ZO-1, and other proteins such as cingulin provide the tightness of the junction.

Assembly, maintenance and function of TJ complexes involve TJ protein expression, phosphorylation, and proteinprotein interactions $[3,14,15]$. These processes are related to multiple signaling transduction pathways including enzymes in the protein kinase $\mathrm{C}$ (PKC) and MAPKs families (e.g., extracellular signal-regulated kinase $1 / 2$ or ERK1/2, and p38) [16-23]. In addition, a number of signaling molecules such as cyclic GMP (cGMP) [24, 25], calcium [23, 26, 27], NF- $\kappa \mathrm{B}$ [28], nitric oxide (NO) [5, 29] and vascular endothelial growth factor (VEGF) [30, 31] also render their influence on the assembly and stability of the structure of TJ complexes.

The MAPK signaling pathway has been linked to a broad spectrum of cellular responses to extracellular stimuli such as growth factors and stress $[32,33]$. In addition to the roles in cellular function, growth and survival, MAPK proteins have been linked to formation and structural integrity of the 
TJ $[10,17,18,20,21]$. However, there are discrepancies among scientific reports on MAPK activities, which may be related to the cell culture system, the culture conditions and the timing of experimentation. For example, ERK1 has been found to interact with occludin in epithelial cells and is required for proper distribution and organization of the TJ proteins and actin cytoskeleton $[10,17]$. Inhibition of MEK-1/2 (MAPK/ERK-1/2) can prevent barrier formation and upregulation of the TJ protein claudin-2 in epithelial cells [34]. By contrast, activation of ERK $1 / 2$ in the transfected MDCK cells with an activated Ras mutant has been reported to increase in the transepithelial permeability of mannitol by six-fold, along with a disappearance of occludin from cellcell contact sites [17]. In addition, the ERK1/2 inhibitor PD98059 could prevent the disruption in barrier function that was induced by cyclosporine $A$ via activation of ERK1/2 MAP signaling cascade in the MDCK monolayers [35]. Thus, the roles of MAPK activities in TJ regulation are quite complicated and need further elucidation.

\section{DISRUPTION OF TIGHT JUNCTIONS}

Disruption of TJ assembly and function can be resulted from a number of conditions such as oxidative stress, inflammation and alcohol exposure [7, 8, 10, 35-38]. Oxidative stress interferes with several cellular homeostasis and functions, leading to the pathological stress such as increase in intracellular $\mathrm{Ca}^{2+}$ and activation of the protein kinase family [18, 20, 27, 39]. Hence, oxidative stress has been linked to several degenerative diseases and pathological states such as Alzheimer's disease, Parkinson's disease, ischemia/reperfusion injuries, inflammation, seizures, stroke, and trauma. In epithelial and endothelial tissues, oxidative stress destabilizes the TJ complexes, leading to an increase in paracellular permeability and barrier leakage $[17,18,20,21,40,41]$. For example, $\mathrm{H}_{2} \mathrm{O}_{2}$ increases the permeability of several epithelial and endothelial barrier models through disruption of the TJ structure [18, 42-44]. The mechanisms of oxidative stress-induced barrier disruption are still incompletely understood. However, several lines of evidence indicate that oxidative damages affect the expression, localization and organization of TJ regulatory proteins, in particular occludin, ZO- 1 and claudins $[14,15,30,34,38,45]$. It was demonstrated that a decrease in occludin protein was responsible for a barrier leakage and loss of transepithelial resistant (TER) values in bovine pulmonary artery endothelial cells treated with $\mathrm{H}_{2} \mathrm{O}_{2}[18,46] . \mathrm{H}_{2} \mathrm{O}_{2}$-induced hyperpermeability of epithelial monolayers has been linked to a decrease in expression and localization of occludin and ZO-1 proteins. This was evidenced by a reduction in their amounts from the western blot analysis along with the discontinuous pattern at the circumferential cell border from immunofluorescent staining of these two junctional proteins [44].

Oxidative stress is able to trigger signaling pathways in TJs regulation involving MAPKs (especially ERK1/2, p38, and c-Jun NH2-terminal kinase or JNK), PKC, phosphodiesterase, small $\mathrm{G}$ protein Rho, and intracellular $\mathrm{Ca}^{2+}[17,19-$ $21,26,37,38,47,48]$. Oxidative stress-induced hyperpermeability is related to phosphorylation of occludin and ZO-1 at the tyrosine residues, downregulation of occludin and activation of MAPK signaling pathways [17, 18]. Consequently, the dissociation of these junctional proteins from the actin cytoskeleton along with redistribution from the junc- tional area takes place $[14,15]$. These processes can be protected with VEGF and EGF through the alteration of ERK and ERK1/2 activity [10]. Kevil et al. (2000) demonstrated that HUVEC treated with $\mathrm{H}_{2} \mathrm{O}_{2}$ at the concentration of 500 $\mu \mathrm{M}$ for $3 \mathrm{hrs}$ resulted in hyperpermeability corresponding to ERK1/2 activation and disorganization of occludin and ZO-1 at the cell-cell contact sites [18]. Huot et al. (1997) also showed that $\mathrm{H}_{2} \mathrm{O}_{2}$ administration caused an early increase in ERK1/2 activity, and a more prolonged increase in p38 MAPK activity [49]. Application of the specific ERK1/2 inhibitor (PD98059) can inhibit the oxidative stress-induced hyperpermeability and affects the redistribution of occludin [18]. Treatment with the p38 inhibitor (SB202190) attenuates an increase in solute permeability in the model of human endothelial cells exposed to $\mathrm{H}_{2} \mathrm{O}_{2}$ [50]. Furthermore, the permeability increasing effects of $\mathrm{H}_{2} \mathrm{O}_{2}$ may be related to an activation of PKC along with a rising of intracellular $\mathrm{Ca}^{2+}$ $[48,51]$. The increase in intracellular $\mathrm{Ca}^{2+}$ activates $\mathrm{Ca}^{2+} /$ calmudulin kinases, which subsequently activates all three MAPKs (ERK, JNK, and p38) [52].

\section{QUERCETIN AND ITS POTENTIAL TO MAINTAIN THE INTEGRITY OF TIGHT JUNCTION}

Recently, there are a number of investigations searching for compounds with barrier protective activities. Growing evidence suggests that certain food components such as glutamine, polyunsaturated fatty acid (PUFA) and flavonoids may be TJ modulators that maintain or enhance TJ integrity and function $[8,9]$.

Quercetin is one of the most widely distributed flavonoids in plants. This polyphenolic compound is found abundantly in fruits and vegetables including apples, onions, berries, beans as well as in food products and beverages derived from plants such as olive oil, tea, and red wine [53-55]. It is also found as a major component in several herbal medicines including Ginkgo biloba, Hypericum perforatum (St. John's Wort), Sambucus canadensis (elder), Vaccinium macrocarpon (cranberry) and Oenothera biennis (evening primrose). Similar to other flavonoids, quercetin contains a broad spectrum of pharmacological and clinically relevant activities including carcinostatic, anti-inflammatory, and antioxidant actions [53, 55-57]. It has been found to suppress cell proliferation, modify eicosanoid synthesis, prevent platelet aggregation, stabilize immune cells, and promote relaxation of vascular smooth muscle [55]. As an antioxidant, quercetin is reported to protect oxidative injuries as well as inflammatory-related injuries [58-60]. The action of quercetin has been linked to a number of enzymes involved in proliferation and signal transduction pathways including PKC, tyrosine kinase, PI-3 kinase, NF- $\kappa$ B, and the MAPK family [55, 6164]. As abovementioned, alteration in the activity of these kinases (PKC and MAPKs in particular) and their sequential signaling pathways significantly influence the assembly and integrity of TJ structure. Thus, it can be hypothesized that quercetin can be a barrier protective agent through its capability to preserve TJ integrity and function.

Although the reported actions of quercetin on barrier functions are quite limited, a growing body of evidence suggests that quercetin can influence the epithelial barrier integrity and function via modulation of structural $\mathrm{TJ}$ proteins $[44,65,66]$. Treatment of Caco-2 monolayers, which is a 
known model of the intestinal epithelium, with quercetin for $48 \mathrm{hrs}$ enhanced barrier functions, as evidenced by an increase in TER values [65]. These findings are related to an increase in claudin- 4 expression $[65,66]$. The study of Suzuki and Hara (2009) further demonstrated that the influence of quercetin during the 48-hr exposure on TJ assembly was biphasic and time-dependent. In the early phase, quercetin promotes TJ assembly and interaction with actin cytoskeleton through distribution of TJ proteins ( $\mathrm{ZO}-2$, claudin-1, and occludin) [66]. During the later phase, expression of claudin4 increases [66]. This promotive effect of quercetin on TJ assembly and barrier functions may be related to the inhibitory action on PKC and its signal transduction pathway, but not to the antioxidant action [65]. Myricetin, which is a more potent antioxidant than quercetin, does not have intestinal barrier enhancing effect in the model of Caco-2 monolayers [65].

Our laboratory is interested in the protective ability of quercetin against oxidative stress-induced breakdown of epithelial and endothelial barriers. Recently, we demonstrated that quercetin was able to prevent the breakdown of barrier functions and the disintegration of $\mathrm{TJ}$ complexes in the ECV304 monolayers upon exposure to non-lethal concentrations of $\mathrm{H}_{2} \mathrm{O}_{2}(100 \mu \mathrm{M} ; 4 \mathrm{hrs})$ [44]. Pretreatment the cells with quercetin $(10 \mu \mathrm{M} ; 30 \mathrm{~min})$ prior to $\mathrm{H}_{2} \mathrm{O}_{2}$ could preserve the normal levels of ZO-1 and occludin expression as well as their localization at the cell border. The integrity of TJ complexes in the quercetin pretreated group was also maintained as evidenced by an increase in TER values and a decrease in phenol red permeability in comparison with the group treated with only $\mathrm{H}_{2} \mathrm{O}_{2}$. In addition, quercetin could suppress $\mathrm{H}_{2} \mathrm{O}_{2}$-mediated activation of $\mathrm{p} 38$ MAPK whereas it potentiated the effect of $\mathrm{H}_{2} \mathrm{O}_{2}$ on ERK1/2 activities. Although the molecular targets of quercetin were not yet identified, our findings suggested that the protective effects of quercetin might involve the altered MAPK activities, in particular the decrease in p38 MAP signaling.

\section{CONCLUSION}

Endothelium/epithelium barriers can be primary targets of oxidative assaults, leading to functional abnormalities associated with the collapse of $\mathrm{TJ}$ structure. As a result, changes in paracellular solute permeability can be observed in correlation with the loss of expression and disorganization of TJ proteins. Quercetin, an edible flavonoid, has been demonstrated its benefit in enhancing $\mathrm{TJ}$ assembly and in preserving TJ integrity and function against $\mathrm{H}_{2} \mathrm{O}_{2}$-mediated TJ disruption that leads to hyperpermeability of epithelial barriers. The TJ modulating effects of quercetin involves with PKC and MAPK activities and their subsequent signaling cascades. The TJ protective activities of quercetin might be clinically beneficial in reducing the potential threat to the organ system and to preserve a normal physiological state of the blood-organ barrier.

\section{CONFLICTS OF INTEREST}

The authors declare no conflicts of interest.

\section{ACKNOWLEDGEMENTS}

None declared.

\section{REFERENCES}

[1] Vandenbrougcke E, Mehta D, Minshall R, Malik AB. Regulation of endothelial junctional permeability. Ann NY Acad Sci 2008; 1123: 134-45.

[2] Gobe GC, Johnson DW. Distal tubular epithelial cells of the kidney: Potential support for proximal tubular cell survival after renal injury. Int J Biochem Cell Biol 2007; 39: 1551-61.

[3] Paris L, Tonutti L, Vannini C, Bazzoni G. Structural organization of the tight junctions. Biochim Biophys Acta 2008; 1778: 646-59.

[4] Tsukita S, Furuse M. Occludin and claudin in tight junction strand: leading or supporting player? Trends Cell Biol 1999; 9: 268-73.

[5] Mark KS, Davis TP. Cerebral microvascular change in permeability and tight junctions induced by hypoxia-reoxygenation. Am J Physiol Heart Circ Physiol 2002; 282: H1485-94.

[6] Aijaz S, Balda MS, Matter K. Tight junctions: Molecular architecture and function. Int Rev Cytol 2006; 248: 261-98.

[7] Sawada N, Murata M, Kikuchi K, et al. Tight junction and human diseases. Med Electron Microsc 2003; 36: 147-56.

[8] Hering NA, Schulzke JD. Therapeutic options to modulate barrier defects in inflammatory bowel disease. Dig Dis 2009; 27: 450-54.

[9] Amasheh M, Andres S, Amasheh S, Fromm M, Schulzke JD. Barrier effects of nutritional factors. Ann NY Acad Sci 2009; 1165: 267-73.

[10] Basuroy S, Seth A, Elias B, Naren AP, Rao R. MAPK interacts with occludin and mediates EGF-induced prevention of tight junction disruption by hydrogen peroxide. Biochem J 2006; 393: 69-77.

[11] Balda MS, Matter K. Transmembrane proteins of tight junctions. Semin Cell Dev Biol 2000; 11: 281-9.

[12] Gonzàlez-Mariscal L, Betanzos A, Nava P, Jaramillo BE. Tight junction proteins. Prog Biophys Mol Biol 2003; 81: 1-44.

[13] Van Itallie CM, Fanning AS, Bridges A, Anderson JM. ZO-1 stabilizes the tight junction solute barrier through coupling to the perijunctional cytoskeleton. Mol Biol Cell 2009; 20: 3930-40.

[14] Kale G, Naren AP, Sheth P, Rao RK. Tyrosine phosphorylation of occludin attenuates its interactions with ZO-1, ZO-2, and ZO-3. Biochem Biophys Res Commun 2003; 302: 324-9.

[15] Rao RK, Basuroy S, Rao VU, Karnaky KJ, Gupta A. Tyrosine phosphorylation and dissociation of occludin-ZO-1 and E-cadherin-betacatenin complexs from the cytoskeleton by oxidative stress. Biochem J 2002; 368: 471-81.

[16] Gonzàlez-Mariscal L, Tapia R, Chamorro D. Crosstalk of tight junction components with signaling pathways. Biochim Biophys Acta 2008; 1778: 729-56.

[17] Chen Y, Lu Q, Schneeberger EE, Goodenough DA. Restoration of tight junction structure and barrier function by downregulation of the mitogen-activated protein kinase pathway in ras-transformed MadinDarby canine kidney cells. Mol Biol Cell 2000; 11: 849-62.

[18] Kevil CG, Oshima T, Alexander B, Coe LL, Alexander JS. $\mathrm{H}_{2} \mathrm{O}_{2}$ mediated permeability: role of MAPK and occludin. Am J of Physiol. Cell Physiol 2000; 279: C21-30.

[19] Fialkow L, Chan CK, Rotin D, Grinstein S, Downey GP. Activation of the mitogen-activated protein kinase signaling pathway in neutrophil. J Biol Chem 1994; 269: 31234-42.

[20] Guyton KZ, Liu Y, Gorospe M, Xu Q, Holbrook NJ. Activation of mitogen-activated protein kinase by $\mathrm{H}_{2} \mathrm{O}_{2}$. J Biol Chem 1996; 271 : 4138-42.

[21] Usatyuk PV, Natarajan V. Role of mitogen-activated protein kinases in 4-hydroxy-2-nonenal-induced actin remodeling and barrier function in endothelial cells. J Biol Chem 2004; 279: 11789-97.

[22] Mullin JM, Kampherstein JA, Laughlin KV, et al. Overexpression of protein kinase C-delta increases tight junction permeability in LLCPK1 epithelia. Am J of Physiol. 1998; 275: C544-C54.

[23] Balda MS, Gonzàlez-Mariscal L, Contreras RG, et al. Assembly and sealing of tight junctions: possible participation of G-proteins, phospholipase C, protein kinase C and calmodulin. J Membr Biol 1991; 122: 193-202.

[24] Chi OZ, Liu X, Weiss HR. Effects of cyclic GMP on microvascular permeability of the cerebral cortex. Microvasc Res 1999; 58: 35-40.

[25] Lee NPY, Cheng CY. Regulation of sertoli cell tight junction dynamics in the rat testis via the nitric oxide synthase/soluble guanylate cyclase/3',5'-cyclic guanosine monophosphate/protein kinase G signaling pathway: an in vitro study. Endrocrine 2003; 144: 3144-3129.

[26] Brown RC, Davis TP. Calcium modulation of adherens and tight junction function: After stroke. Stroke 2002; 33: 1706-11.

[27] Tiruppathi C, Minshall RD, Paria BC, Vogel S, Malik AB. Role of $\mathrm{Ca}^{2+}$ signaling in the regulation of endothelial permeability. Vascul Pharmacol 2002; 39: 173-85. 
[28] Ma TY, Iwamoto GK, Hoa NT, et al. TNF- $\alpha$-induced increase in intestinal epithelial tight junction permeability requires $\mathrm{NF}-\kappa \mathrm{B}$ activation. Am J Physiol Gastrointest Liver Physiol 2004; 49: G367-G76.

[29] Chua CC, Hamdy RC, Chua BH. Upregulation of vascular endothelial growth factor by $\mathrm{H}_{2} \mathrm{O}_{2}$ in rat heart endothelial cells. Free Radic Biol Med 1998; 25: 891-7.

[30] Fischer S, Wobben M, Marti HH, Renz D, Schaper W. Hypoxiainduced hyperpermeability in brain microvessel endothelial cells involves VEGF-mediated changes in the expression of zonula occludens-1. Microvasc Res 2002; 63: 70-80.

[31] Antonetti DA, Barber AJ, Hollinger LA, Wolpert EB, Gardner TW. Vascular endothelial growth factor induces rapid phosphorylation of tight junction proteins occludin and zonula occluden 1. J Biol Chem 1999; 274: 23464-7.

[32] Yosimichi G, Nakanishi T, Nishida T, Hattori T, Takano-Yamamoto T, Takigawa M. CTGF/Hcs24 induceds chondrocyte differentiation through a p38 mitogen-activated protein kinase (p38 MAPK), and proliferation through a p44/42MAPK/extracellular-signal regulated kinase (ERK). Eur J Biochem 2001; 268: 6058-5065.

[33] Waskiewicz AJ, Cooper JA. Mitogen and stress response pathways: MAP kinase cascades and phosphatase regulation in mammals and yeast. Curr Opin Cell Biol 1995; 7: 798-805.

[34] Kinugasa T, Sakaguchi T, Gu X, Reinecker HC. Claudins regulate the intestinal barrier in response to immune mediators. Gastroenterology 2000; 118: 1001-11.

[35] Kiely B, Feldman G, Ryan P. Modulation of renal epithelial barrier function by mitogen-activated protein kinases (MAPKs): Mechanism of cyclosporine A-induced increase in transepithelial resistance. Kidney Int 2003; 63: 908-16.

[36] Wang Y, Zhang J, Yi XJ, Yu FS. Activation of ERK1/2 MAP kinase pathway induces tight junction disruption in human corneal epithelial cells. Exp Eye Res 2004; 78: 125-36.

[37] Bruewer M, Samarin S, Nusrat A. Inflammatory bowel disease and the apical junctional complex. Ann NY Acad Sci 2006; 1072: 242-52.

[38] Harhaj NS, Antonetti DA. Regulation of tight junctions and loss of barrier function in pathophysiology. Int J Biochem Cell Biol 2004; 36: 1206-37.

[39] Pariente JA, Camello C, Camello PJ, Salido GM. Release of calcium from mitochondrial and nonmitochondrial intracellular stores in mouse pancreatic acinar cells by hydrogen peroxide. J Membr Biol 2001; 179: 27-35.

[40] Zhao Y, Davis HW. Hydrogen peroxide-induced cytoskeletal rearrangement in cultured pulmonary endothelial cells. J Cell Physiol 1998; 174: 370-9.

[41] Vepa S, Scribner WM, Parinandi NL, English D, Garcia JG, Natarajan V. Hydrogen peroxide stimulates tyrosine phosphorylation of focal adhesion kinase in vascular endothelial cells. Am J Physiol 1999; 277: L150-8.

[42] Meyer TN, Schwesinger C, Ye J, Denker BM, Nigam SK. Reassembly of the tight junction after oxidative stress depends on tyrosine kinase activity. J Biol Chem 2001; 276: 22048-55.

[43] Jepson MA. Disruption of epithelial barrier function by $\mathrm{H}_{2} \mathrm{O}_{2}$ : distinct responses of Caco-2 and Mardin-Darby canine kidney (MDCK) strains. Cell Mol Biol 2003; 49: 101-12.

[44] Chuenkitiyanon S, Pengsuparp T, Jianmongkol S. Protective effect of quercetin on hydrogen peroxide-induced tight junction disruption. Int J Toxicol 2010; 29: 418-24.

[45] Krizbai IA, Bauer H, Bresgen N, et al. Effect of oxidative stress on the junctional proteins of cultured cerebral endothelial cells. Cell Mol Neurobiol 2005; 25: 129-39.

[46] Kevil CG, Ohno N, Gute DC, et al. Role of cadherin internalization in hydrogen peroxide-mediated endothelial permeability. Free Radic Biol Med 1998; 24: 1015-22.
[47] Siflinger-Birnboim A, Goligorsky MS, Del Vecchio PJ, Malik AB. Activation of protein kinase $\mathrm{C}$ pathway contributes to hydrogen peroxide-induced increase in endothelial permeability. Lab Invest 1992; 67: 24-30.

[48] Lum H, Barr DA, Shaffer JR, Gordon RJ, Ezrin AM, Malik AB Reoxygenation of endothelial cells increases permeability by oxidantdependent mechanisms. Circ Res 1992; 70: 991-8.

[49] Huot J, Houle F, Marceau F, Landry J. Oxidative stress- induced actin reorganization mediated by the $\mathrm{p} 38$ mitogen-activated protein kinase/heat shock protein 27 pathway in vascular endothelial cells. Circ Res 1997; 80: 383-92.

[50] Kevil CG, Oshima T, Alexander JS. The role of p38 MAP kinase in hydrogen peroxide-mediated endothelial solute permeability. Endothelium 2001; 8: 107-16.

[51] Siflinger-Birnboim A, Lum H, Del Vecchio PJ, Malik AB. Involvement of $\mathrm{Ca}^{2+}$ in the $\mathrm{H} 2 \mathrm{O} 2$-induced increase in endothelial permeability. Am J Physiol 1996; 270: L973-8.

[52] Nimnual AS, Yatsula BA, Bar-Sagi D. Coupling of Ras and Rac guanosine triphosphatases through the Ras exchange. Science 1998; 279: 560-3.

[53] Croft KD. The chemistry and biological effects of flavonoids and phenolic acids. Ann NY Acad Sci 1998; 854: 435-42

[54] Hertog MG, Hollman PC. Potential health effects of the dietary flavonol quercetin. Eur J Clin Nutr 1996; 50: 63-71.

[55] Formica JV, Regelson W. Review of the biology of quercetin and related bioflavonoids. Food Chem Toxicol 1995; 33: 1061-80.

[56] Middleton E Jr. Effect of plant flavonoids on immune and inflammatory cell function. Adv Exp Med Biol 1998; 439: 175-82.

[57] Erlund I, Freese R, Marniemi J, Hakala P, Alfthan G. Bioavailability of quercetin from berries and the diet. Nutr Cancer. 2006; 54: 13-7.

[58] Heo HJ, Lee CY. Protective efects of quercetin and vitamin C against oxidative stress-induced neurodegenaration. J Agric Food Chem 2004; 52: 7514-7

[59] Chen JC, Ho FM, Pei-Dawn LC, et al. Inhibition of iNOS gene expression by quercetin is mediated by the inhibition of I(Kappa)B kinase, nuclear factor-kappa B and STAT1, and depends on heme oxygenase-1 induction in mouse BV-2 microglia. Eur J Pharmacol 2005; 521: 9-20.

[60] Dok-Go H, Lee KH, Kim HJ, et al. Neuroprotective effects of antioxidative flavonoids, quercetin (+)-dihydroquercetin and quercetin 3-methyl ether, isolated from Opuntia ficus-indica var. saboten. Brain Res 2003; 965: 1306

[61] Agullo G, Gamet-Payrastre L, Manenti S, et al. Relationship between flavonoid structure and inhibition of phosphatidylinositol 3kinase: A comparison with tyrosine kinase and protein kinase $\mathrm{C}$ inhibition. Biochem Pharmacol 1997; 53: 1649-57.

[62] Gamet-Payrastre L, Manenti S, Gratacap MP, Tulliez J, Chap H, Payrastre B. Flavonoids and the inhibition of PKC and PI-3 kinase. Gen Pharmacol 1999; 32: 279-86.

[63] Ishikawa Y, Sugiyama H, Stylianou E, Kitamura M. Bioflavonoid quercetin inhibits interleukin-1-induces transcriptional expression of monocyte chemoattractant protein-1 in glomerular cells via suppression of nuclear factor- $\kappa$ B. J Am Soc Nephrol 1999; 10: 2290-6.

[64] Lin R, Liu J, Gan W, Ding C. Protective effect of quercetin on the homocysteine-injured human umbilical vein vascular endothelial cell line (ECV304). Basic Clin Pharmacol Toxicol 2007; 101: 197-202.

[65] Amasheh M, Schlichter S, Amasheh S, et al. Quercetin enhances epithelial barrier function and increases claudin-4 expression in Caco2 cells. J Nutr 2008; 138: 1067-73

[66] Suzuki T, Hara H. Quercetin enhance intestinal barrier function through the assembly of zonnula occludin-2, occludin-1 and the expression of claudin-4 in Caco-2 cells. J Nutr 2009; 139: 965-74. 